\title{
A Study of Family Education and Its Improving Strategies in Qingyuan City of China in the "Internet Plus" Era
}

\author{
Shufen Huang ${ }^{1, *}$ \\ ${ }^{1}$ School of Tourism, Housekeeping and Arts, Qingyuan Polytechnic, Qingyuan, Guangdong 511510, China \\ *Corresponding author. Email: hsfecho@163.com
}

\begin{abstract}
Family education is an important part of children's education. Being Aware of the important impacts of family education on children's development, the Chinese government and education departments have formulated and promulgated "The Family Education Promotion Law" to further clarify family responsibilities, state supports and social coordination. In this study, parents in Qingyuan City the researcherre selected for investigation. It is found that most parents in Qingyuan City take a full-time job and take care of their families at the same time. It was also discovered that the negative family communication was common, and that the parent-led parenting model was prominent. This article suggests that by using the convenient, open, individual and intelligent Internet plus technology, it is necessary to develop the family education comprehensive learning platform, family education research platform and family education quality evaluation center to further improve the quality of family education.
\end{abstract}

Keywords: Family education, Growing parents, Integrated learning platform, Research and evaluation.

\section{INTRODUCTION}

Family education is an important part of children's education. The quality of family education directly affects the quality of personal life and social harmony. The state is also aware of the importance of family education, working to enhance parents' awareness of family responsibility and improve parents' ability in doing family education. Since 2015, the National People's Congress Deputies have put forward a proposal on the formulation of the Family Education Promotion Law. In 2021, the National People's Congress has adopted the law, which has clarified family responsibilities, state supports and social coordination for family education. [1]

*Fund: This article was sponsored by Young Talent Socia Science Research Fund of Guangdong Provincial Department of Education for the year of 2018 (grant number:2018GWQNCS140 ) and Educational Research Fund of Qingyuan City (grant number:19-96).

\section{RESARCH QUESTIONS}

Obviously, both at the national level and at the individual level, many subjects hope to further improve the quality of family education and provide the best environments for children. However, the questions are:

(A)Do parents have enough time for family education?

(B)Do they have appropriate parenting skills?

(C)What is the common parenting model of parents?

This study takes Qingyuan City as an example and collects data from parents whose children under 14 years old. As the largest land area in Guangdong province, Qingyuan is located in the north of Guangdong Province. By the end of 2019, the number of registered residence population reached 4.46 million and 400, among which 1.53 million the researcherre under the young under 18 years old. [2] With the help from local schools and education 
departments in Qingyuan, the researcher got 107385 valid questionnaires in this survey which help us come to understand more about the current situation of family education in the area.

\section{THE CURRENT SITUATION OF FAMILY EDUCATION IN QINGYUAN}

\subsection{On-The-job Parents Take the Highest Proportion}

The way parents work largely determines the time parents can spend with their children. According to the survey, $74.26 \%$ of parents have stable jobs, of which $62.5 \%$ work more than 8 hours a day, and $20 \%$ often work overtime. It can be seen that most parents need to struggle with the fatigue of full-time work and the responsibility of family upbringing. Surprisingly, $92.19 \%$ of the surveyed parents have a high school or lower education. Their low education level not only affects their employment but also their knowledge and skills of family upbringing.

\subsection{There Is Negative Communication Between Parents and Children}

In this questionnaire survey, questions were set to ask about the communication mode, communication feeling, communication effects and other dimensions about communication among parents and children. Firstly, 80.09\% of parents hope to use the strategy of setting an example for parenting; however, $68.35 \%$ of parents have used negative communication methods with their children, such as criticism, flattery, nagging and so on. Secondly, more than $30.5 \%$ of parents often feel annoyed because of poor communication with their children, and $61.4 \%$ of parents occasionally encounter the same problem, while only $8 \%$ do not have such problem at all. Thirdly, from the effect of communication, $5.9 \%$ of parents think that children will not share their fun and troubles with them at all, and it is difficult for parents to enter their children's inner world, while in $57.57 \%$ of families children occasionally share their fun and inner troubles with parents.

\subsection{Although It Is Required to Show Equality, Most Parents Choose Parental-led Parenting}

The parenting style in a family directly affects the quality of family education. This survey is to understand the parenting style of parents in terms of whether they have a strict attitude towards children, whether they will consider their children's priority while making decisions, whether they will interfere children's making friends and whether they will take the initiative to apologize when they do wrong.

The survey found that: firstly, parents who are very strict with their children account for $28.78 \%$, and those who are occasionally strict account for $69.14 \%$. Among parents with strict attitudes, the proportion of children who are unwilling to share their inner thoughts with their parents is also relatively high. Secondly, no matter what age children are, when parents think they are doing the right thing for their children, $61.15 \%$ of parents will not consider their children's opinions and priorities when making decisions. It can be seen that most parents are strong-minded and prefer parental-led family life. Thirdly, when asked whether they would interfere their children from making friends with children with poor grades, most parents, more than $93.55 \%$ of them, think they will not interfere, but $34 \%$ will be moderately wary. Forth, when they found their mistakes, $52.11 \%$ of the parents often apologize to their children, neglecting their parental authority. The parents who can take the initiative to apologize when dealing with their own mistakes are increasing, indicating that parents are willing to show respect for their children.

\subsection{Generalization of the Current Family Education}

From the above data analysis, the researcher can sum up that: first, most parents work on-the-job, so the time at home is mainly in the evening or the weekend. Therefore, parents' participation in family interaction and education needs to be reasonably arranged. With the characteristics of ubiquity and openness, internet technology and new media platform can help improving family education. Second, most parents need further helps in communication with their children, especially in using positive communication skills and listening skills. Third, most family still prefer parentdominated authority, but parents need to learn how to balance between interfering and neglecting into their children's personal affairs. 


\section{ADVICE ON IMPROVING FAMILY EDUCATION IN THE INTERNET PLUS EAR}

The Internet age makes mobile learning possible. With the characteristics of convenience, openness, personalization and intelligence, Internet technology can be a very good tool for improving family education. the researcher advice the related parties can help to build up a comprehensive family education learning platform, a family education research center and a family education assessment platform, which can update parents' educational values, skills and family education efficiency.

\subsection{Characteristics of Internet Plus Technology}

The available Internet access in everywhere makes it possible to learn everywhere and every time. Mobile phones and Internet technology can help the on-the-job parents to use short breaks to learn family education knowledge and courses. Rather than traditional lectures, multiple media forms of learning resources can be adapted.

The openness of Internet means multiple subjects providing training on family education and rich educational resources. [3] The openness of the Internet has attracted more Internet enterprises and educational institutions to carry out more diversified supply of family education resources, so that family education resources can change from traditional lectures to more lively and vivid forms, and enhance parents' interest in self-learning and personal growth in family upbringing.

Internet's characteristic of personalization means that every parent can have their own preferences and priorities in choosing family education learning resources and services according to their own needs. The Internet takes personalized customization as the basic form, which can provide personalized educational content and mode according to different groups of parents, so as to improve the user experience. For example, the personalization of the Internet can provide corresponding educational resources for single parent families, families with special children and divorced families.

Intelligence is a very important characteristic of internet technology and big data. It means the researcher can make advantage of big data to collect information in all directions, helping parents and children to conduct self-analysis and evaluation. In some ways, it will assess the quality of family education more smartly and intelligently.

\subsection{Advice on Using Internet Plus Technology for Improving Family Education}

\subsubsection{Building up an Integrated Learning Platform for Family Education by Using Internet Plus Technology}

The primary task of improving the quality of family education is to improve parents' family education concepts and skills. Taking advantage of Internet plus technology, the researcher can build up a localized family education comprehensive learning platforms, aiming at improving parents' knowledge, skills and self-confidence in family education. [4] With the help of large statistical data, the platform will pay attention to the users ' learning experience, making accurate analysis according to parents' learning interests, learning abilities, learning advantages and learning habits. Then the platform will provide targeted resources and services for them. According to the current situation of family education in Qingyuan area, the platform may provide them more resources on parent-child communication skills, leading to more positive communication.

\subsubsection{Building up a Family Education Research Center by Using Internet Plus Technology}

The construction of family education integrated learning platform is inseparable from the support of related researches. Therefore, in order to ensure parents' efficient and high-quality learning, the construction of family education research center has become inevitable. Using the Internet plus technology, the researcher are able to establish a collaborative mechanism of parent learning and research doing, and able to set up a collaborative innovation center specializing in family education and parenting. [5] It will launch long-term researches on the issues of parental learning, parental guidance, parents' learning resources design and development, parents' learning network effectiveness, parents' information literacy and so on. 


\subsubsection{Building up the Evaluation Center of Family Education by Using Internet Plus Technology}

Whether it is national legislation or the Internet family education integrated learning platform, every force committed to promoting the quality of Chinese family education ultimately needs to rely on evaluation to test its effectiveness. Therefore, the construction of family education evaluation center by Internet plus technology is needed. By constructing a scientific and reasonable family education evaluation system, the researcher can improve the quality of family education accordingly. [6] In particular, the researcher should guide the direction of family development, adhere to the educational purpose of "Building Morality and Cultivating People" rather than the views of "Score the Highest" or "Only Academic Ability Counts". The family education evaluation center can provide scientific and reasonable assessments for further decision-making on the issues of policy making, regional supporting and strategies made by individual family.

\section{CONCLUSION}

In short, the importance of family education deserves the joint efforts of the government, schools and families, who need to actively give full play to the advantages of convenience, openness, personalization and intelligence of internet technology. The researcher advice to develop a integrated learning platform for family education, a family education research center and a family education evaluation center, which can be possible to further improve the quality of family education. No doubt, no amount of internet resources or research can work effectively without parents' real-life interactions with children. Parents expressing their love and appreciation to their children and guiding them to a more mature life with their own wisdom is the key for better family education.

\section{AUTHORS' CONTRIBUTIONS}

This paper is independently completed by Shufen Huang.

\section{ACKNOWLEDGMENTS}

My deepest thanks are given to the Women's Federation and the Education Bureau of Qingyuan City who have helped us conduct the survey. Those anonymous parents who have kindly shared their needs and struggles in rearing their children are greatly appreciated. Without these people the research and study won't be able to be completed.

\section{REFERENCES}

[1] The Family Education Law (Draft) is proposed to change its name to the family education promotion law. [n / OL] (2011-817)

[2021-9-10]. http://www.npc.gov.cn/npc/c30834/202108/30 961143434c4aa399e5c7a0e352a38d.shtml.

[2] 2020 Qingyuan Yearbook. [n / OL] (2020-1230) [2021-09-10]. http://www.gdqy.gov.cn/xxgk/zzjg/zfjg/qystjj/ tjxx/tjnj/content/post_1325921.html.

[3] Li Tongtong. Compulsory to Voluntary: Path of Action to Family Education in the Internet Plus Era [J]. Adult Education in China, 2019 (16): 60-64.

[4] Wang Jingwen. Impacts of Internet Technology on Parenting Education and Improving Suggestions [J]. Adult Education in China , 2018 (23): 64-67.

[5] Mao the researchernxiu, Chen Lin, etc.. New formats of Parent Learning in the Age of Wise Internet [J]. Modern Educational Technology, 2021 (03): 104-110.

[6] Lu Dong, Lu Shenglin. “Improve the Family Education System and Unite the Joint Efforts of Family and School Education" [J]. China Moral Education, 2019 (01): 60-62 